\title{
BMJ Open Community characteristics associated with where urgent care centers are located: a cross-sectional analysis
}

\author{
Sidney T Le, ${ }^{1}$ Renee Y Hsia ${ }^{2}$
}

To cite: Le ST, Hsia RY. Community characteristics associated with where urgent care centers are located: a cross-sectional analysis. BMJ Open 2016;6: 010663. doi:10.1136/bmjopen-2015010663

- Prepublication history and additional material is available. To view please visit the journal (http://dx.doi.org/ 10.1136/bmjopen-2015010663).

Received 24 November 2015 Revised 3 February 2016 Accepted 28 February 2016

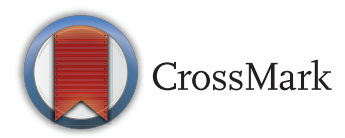

\footnotetext{
${ }^{1}$ School of Medicine, University of California at San Francisco, San Francisco, California, USA

${ }^{2}$ Department of Emergency Medicine, Philip R. Lee Institute for Health Policy Studies, University of California at San Francisco, San Francisco, California, USA
}

Correspondence to Dr Renee Y Hsia; renee.hsia@ucsf.edu

\section{ABSTRACT}

Objectives: To determine the community characteristics associated with non-hospital-based urgent care centres wherever they are located.

Design: National cross-sectional study evaluating the association between non-hospital-based urgent care centers, and their demographic characteristics in a community, using descriptive statistics and multivariate logistic regressions.

Setting: Communities in the USA with non-hospitalbased urgent care centers, as identified using a 2014 national database from the Urgent Care Association of America.

Participants: 31022 communities encompassing 6898 urgent care centers across the USA.

Primary and secondary outcome measures: Presence of a non-hospital-based urgent care center within a community.

Results: Communities with non-hospital-based urgent care centers are urban $(75.7 \%$ with vs $22.2 \%$ without; $p<0.001$ across rural urban commuting area levels), and are located in areas with higher income levels (38.6\% in highest quartile with vs $22.3 \%$ without; $p<0.001$ across quartiles) and higher levels of private insurance $(29.6 \%$ in highest quartile with vs $23.9 \%$ without; $p<0.001$ across quartiles).

Conclusions: While the growth of the urgent care industry may have other promising implications, policymakers should recognise that it may exacerbate disparities in access to acute care faced by poorer, uninsured patients, and may also have financial implications for providers that are providing overlapping services, such as emergency departments and primary care practices.

\section{INTRODUCTION}

The rapidly growing urgent care centre (UCC) industry is a popular source of primary and non-emergency care services. Since 2004, an estimated 300 new sites have opened annually, currently totalling about 8000 centres nationally. ${ }^{12}$ These centres typically open during extended weekday and weekend hours, accept unscheduled visits, and provide low-acuity to mid-acuity episodic

\section{Strengths and limitations of this study}

- We used data from the Urgent Care Association of America and American Hospital Association to obtain a list of urgent care centres that are both hospital and non-hospital based.

- We defined community by ZIP codes, as done in previous literature.

- The number of urgent care centres is inconsistently reported in the literature, and despite data validation efforts using phone calls and internet searches, it is unclear how comprehensive our list is.

- Due to lack of patient-level data from urgent care centres, we were unable to directly characterise patients who seek care at urgent care centres, and instead sought to characterise the demographics of communities where urgent care centres are located.

care to patients who would otherwise seek care at emergency departments or by primary care practices. ${ }^{3}$ Along with retail clinics, which unlike UCCs are typically located inside retail or grocery stores and are staffed with non-physician providers, UCCs seek to address the demand for prompt and convenient care, emphasising convenience, shorter wait times, and less administrative hassle. UCCs also have been touted as a partial solution to alleviate the strain resulting from the well-documented national shortage of primary and emergency care resources. ${ }^{4-9}$

There is concern, however, that the proliferation of UCCs may worsen disparities in healthcare access, ${ }^{10}$ and to our knowledge, no study has yet investigated what types of communities have access to urgent care. As the majority of UCCs are physician-owned or backed by substantial venture capital investment, ${ }^{11}$ we hypothesise that in order to ensure favourable returns on investment, these entities may prioritise locations with low concentrations of uninsured populations, as retail clinics do. ${ }^{12}$ In addition, UCCs are 
selective about their payer mix, and provide a lower share of their care to Medicaid and uninsured patients than do emergency departments, which are legally obligated to accept all patients. Like all other healthcare services in the USA, except for emergency departments, UCCs may refuse care to patients if they cannot pay. Finally, UCCs are subject to limited regulation and licencing requirements-for example, Arizona is one of the few states with regulations specific to urgent care. ${ }^{13}$

Despite the proliferation of UCCs, there have been few empirical studies describing the patients who have access to urgent care and the factors that influence where the UCCs are located. To address this gap, we performed an analysis of communities where UCCs exist. Specifically, we sought to answer two questions: first, what are the demographics and characteristics of communities containing UCCs? Second, what are the community factors that influence where the UCCs are located?

\section{METHODS}

\section{Data sources}

We conducted a cross-sectional analysis using national data from the Urgent Care Association of America (UCAOA), a professional association founded in 2004 for UCCs and physicians, which we accessed on 23 July 2014 . UCCs, as broadly defined by UCAOA, are facilities that provide healthcare for acute illness or injury on a walk-in basis and are not emergency departments. ${ }^{14}$ This database lists over 7000 UCCs, which includes UCAOA-accredited centres, centres identified by UCAOA staff, and centres identified through self-report. According to a benchmarking study, this list likely undercounts the number of UCCs that are part of hospitals. ${ }^{2}$ We therefore incorporated data from the American Hospital Association Annual Survey 2012 to identify over another 1000 UCCs. UCCs are located in a variety of settings, so we used public records, phone calls, and Internet searches to identify which UCCs were hospital-based, defined as either being owned by a hospital or as being located within a hospital campus, and which were non-hospital based. We considered UCCs that were owned by a hospital system and jointly run with another organisation as being hospital based.

We merged these data with community characteristics from four datasets: (1) US Census 2010, which contains ZIP code-level demographic data such as age, race and ethnicity; ${ }^{15}$ (2) the American Community Survey 2012's 5 -Year Estimates, ${ }^{16}$ which contains ZIP code-level socioeconomic data such as income levels and private insurance rates; (3) the Area Resource File 2011, ${ }^{17}$ which contains county-level information on primary care resources and (4) rural urban commuting area (RUCA) codes to categorise level of urbanisation. ${ }^{18}$

\section{Primary outcome}

We chose to use non-hospital-based UCCs to define our main outcome, since our goal was to better characterise access to UCCs whose locations are more independently determined, as opposed to hospital-based UCCs, which are, by definition, only available where hospitals already exist. We used the ZIP codes of UCCs to identify communities where UCCs are present and absent, and the presence or absence of UCCs within the community defined our primary outcome. As a sensitivity analysis, we repeated the analyses including hospital-based UCCs, the results of which are available in the online supplementary appendix. As done in other literature, we defined community by ZIP codes, which was our unit of analysis. $^{19} 20$

\section{Predictors}

We identified predictors of interest for the communities, specifically vulnerable populations as defined in other literature. ${ }^{20}{ }^{21}$ We defined per cent minority as the share of the population that is non-white or Hispanic. Per cent private insurance was defined as the share of the population that has insurance through a current or former employer or union, insurance purchased directly from an insurance company, or TRICARE, or other military health coverage. We included indicators for whether the community was in a county that is wholly or partially designated as a primary medical care health professional shortage area (HPSA). This is an annually reviewed designation given by the US Department of Health and Human Services based on a high ratio of population to primary care physician. ${ }^{22}$ We also included the percentage of elderly individuals (age $>65$ years) and the median income level of the community.

\section{Statistical methods}

We calculated descriptive statistics of communities with and without UCCs, and compared those communities using $\chi^{2}$ tests. We then ran multivariate logistic regressions to determine the factors that independently influence whether a UCC exists within that region. In the primary analysis, the logistic model used quartiles of the predictors. As a sensitivity analysis, we performed zero-inflated Poisson regressions, where the outcome was the number of UCCs within the community. As those results were similar to the logistic regression analysis, they are included in online supplementary appendix tables 1 and 2.

We considered a two-tailed $p$ value of $<0.05$ as significant. All analyses were performed using Stata V.13 (College Station, Texas, USA: StataCorp LP). This study was considered exempt by the Committee on Human Research at the University of California San Francisco.

\section{RESULTS}

A total of 31022 communities encompassing 6898 UCCs and over 300 million residents were included in our sample. The number of UCCs is roughly consistent with a 2009 study that had identified 8113 UCCs and estimated that $71.6 \%$ of UCCs are not hospital affiliated. ${ }^{2}$ 
Table 1 Comparison of communities with and without non-hospital-based urgent care centres (UCCs)

\begin{tabular}{|c|c|c|c|}
\hline & Communities without UCCs & Communities with UCCs & Total \\
\hline Number of communities & 26402 & 4620 & 31022 \\
\hline Number of UCCs & & 6898 & 6898 \\
\hline \multirow[t]{2}{*}{ Total population 2010 (in 10000 ) } & 16662 & 13402 & 30064 \\
\hline & Number of communities (\%) & Number of communities (\%) & p Value \\
\hline \multicolumn{4}{|l|}{ RUCA } \\
\hline Urban & $5874(22.2 \%)$ & 3499 (75.7\%) & 0.000 \\
\hline Suburban & $5442(20.6 \%)$ & $353(7.6 \%)$ & \\
\hline Large rural town & $3994(15.1 \%)$ & $468(10.1 \%)$ & \\
\hline Small town or isolated rural area & $11092(42.0 \%)$ & $300(6.5 \%)$ & \\
\hline \multicolumn{4}{|l|}{ Health provider shortage area } \\
\hline Not designated HPSA & $3621(13.7 \%)$ & $605(13.1 \%)$ & 0.008 \\
\hline Part of county designated HPSA & $11568(43.8 \%)$ & $1940(42.0 \%)$ & \\
\hline Whole county designated HPSA & $11212(42.5 \%)$ & 2075 (44.9\%) & \\
\hline \multicolumn{4}{|l|}{ Income (in 1000 US\$) } \\
\hline Lowest quartile $(<\$ 38)$ & $6923(26.2 \%)$ & 757 (16.4\%) & 0.000 \\
\hline Quartile 2 (\$39-\$47) & $6725(25.5 \%)$ & $952(20.6 \%)$ & \\
\hline Quartile $3(\$ 48-\$ 60)$ & $6553(24.8 \%)$ & $1126(24.4 \%)$ & \\
\hline Highest quartile (>\$61) & $5896(22.3 \%)$ & $1782(38.6 \%)$ & \\
\hline \multicolumn{4}{|l|}{ Private health insurance } \\
\hline Lowest quartile (<81.4\%) & $6835(25.9 \%)$ & $897(19.4 \%)$ & 0.000 \\
\hline Quartile 2 (81.5-87.3\%) & $6622(25.1 \%)$ & $1131(24.5 \%)$ & \\
\hline Quartile 3 (87.4-9.20\%) & $6544(24.8 \%)$ & $1224(26.5 \%)$ & \\
\hline Highest quartile (>9.21\%) & $6298(23.9 \%)$ & $1366(29.6 \%)$ & \\
\hline \multicolumn{4}{|l|}{ Minority } \\
\hline Lowest quartile (<2.9\%) & $7828(29.6 \%)$ & $127(2.7 \%)$ & 0.000 \\
\hline Quartile $2(3.0-7.6 \%)$ & $6939(26.3 \%)$ & $689(14.9 \%)$ & \\
\hline Quartile 3 (7.7-22.6\%) & $5884(22.3 \%)$ & $1815(39.3 \%)$ & \\
\hline Highest quartile (>22.7\%) & $5749(21.8 \%)$ & $1989(43.1 \%)$ & \\
\hline \multicolumn{4}{|l|}{ Elderly } \\
\hline Lowest quartile (<12.0\%) & $5942(22.5 \%)$ & $1886(40.8 \%)$ & 0.000 \\
\hline Quartile $2(12.1-15.0 \%)$ & $6609(25.0 \%)$ & $1204(26.1 \%)$ & \\
\hline Quartile 3 (15.1-18.3\%) & $6735(25.5 \%)$ & $910(19.7 \%)$ & \\
\hline Highest quartile (>18.4\%) & $7114(26.9 \%)$ & $620(13.4 \%)$ & \\
\hline Average population & 631 & 2901 & 0.000 \\
\hline
\end{tabular}

The characteristics of communities with and without UCCs are presented in table 1 . The average population in communities with UCCs was substantially higher than in communities without non-hospital-based UCCs (2901 vs $631, \mathrm{p}<0.001)$. Communities with UCCs were generally urban $(75.7 \%$ with UCCs vs $22.2 \%$ without UCCs; $\mathrm{p}<0.001$ across RUCA levels), had higher proportion of minorities (43.1\% in highest quartile with UCCs vs $21.8 \%$ without UCCs; $\mathrm{p}<0.001$ across quartiles), and lower proportion of elderly $(40.8 \%$ in lowest quartile with UCCs vs $22.5 \%$ without UCCs; $\mathrm{p}<0.001$ across quartiles). Communities with UCCs generally had higher income levels $(38.6 \%$ in highest quartile with UCCs vs $22.3 \%$ without UCCs; $\mathrm{p}<0.001$ across quartiles) and had higher levels of private insurance $(29.6 \%$ in highest quartile with UCCs vs $23.9 \%$ without UCCs; $\mathrm{p}<0.001$ across quartiles). The difference in HPSA designation between communities with and without UCCs was modest though significant $(44.9 \%$ in a whole HPSA county, and $42.0 \%$ in a partial HPSA county for communities with UCCs vs $42.5 \%$ in a whole HPSA county, and $43.8 \%$ in a partial HPSA county for communities without UCCs; $p=0.008$ across quartiles).

Table 2 presents the ORs from the logistic regression results. More rural communities were less likely to have UCCs relative to urban communities (OR 0.16, 0.31 and 0.08 for suburban, large rural town and small town or isolated rural area, respectively; $\mathrm{p}<0.001$ for all). HPSA communities were less likely to have a UCC (OR 0.86; $\mathrm{p}=0.01$ for whole county designated HPSA). Communities with higher incomes were more likely to have UCCs; specifically, the highest quartile had a 1.18 OR of having a UCC relative to the lowest quartile ( $p=0.023)$, and those in the second and third quartiles had higher ORs relative to the lowest quartile (1.27 and 1.28 , respectively; $\mathrm{p}<0.001$ for each). Similarly, communities that had a higher percentage of private health insurance were more likely to have a UCC compared with 
Table 2 Logistic regression on likelihood of presence of non-hospital-based urgent care centres within community

\begin{tabular}{|c|c|c|c|}
\hline & Odds ratio & $95 \% \mathrm{Cl}$ & p Value \\
\hline \multicolumn{4}{|l|}{ RUCA } \\
\hline Urban & reference & & \\
\hline Suburban & 0.16 & $(0.14$ to 0.18$)$ & 0.000 \\
\hline Large rural town & 0.31 & (0.28 to 0.35$)$ & 0.000 \\
\hline Small town or isolated rural area & 0.08 & (0.07 to 0.09$)$ & 0.000 \\
\hline \multicolumn{4}{|l|}{ Health provider shortage area } \\
\hline Not designated HPSA & reference & & \\
\hline Part of county designated HPSA & 0.90 & $(0.80$ to 1.00$)$ & 0.059 \\
\hline Whole county designated HPSA & 0.86 & (0.77 to 0.97$)$ & 0.010 \\
\hline \multicolumn{4}{|l|}{ Income } \\
\hline Lowest quartile & reference & & \\
\hline Quartile 2 & 1.27 & (1.12 to 1.43$)$ & 0.000 \\
\hline Quartile 3 & 1.28 & (1.12 to 1.46$)$ & 0.000 \\
\hline Highest quartile & 1.18 & (1.02 to 1.37$)$ & 0.023 \\
\hline \multicolumn{4}{|l|}{ Private health insurance } \\
\hline Lowest quartile & reference & & \\
\hline Quartile 2 & 1.51 & (1.34 to 1.70$)$ & 0.000 \\
\hline Quartile 3 & 1.66 & (1.46 to 1.90$)$ & 0.000 \\
\hline Highest quartile & 1.43 & (1.22 to 1.66$)$ & 0.000 \\
\hline \multicolumn{4}{|l|}{ Minority } \\
\hline Lowest quartile & reference & & \\
\hline Quartile 2 & 4.09 & (3.36 to 4.98 ) & 0.000 \\
\hline Quartile 3 & 8.54 & (7.06 to 10.34 ) & 0.000 \\
\hline Highest quartile & 9.14 & (7.48 to 11.16 ) & 0.000 \\
\hline \multicolumn{4}{|l|}{ Older than 65} \\
\hline Lowest quartile & reference & & \\
\hline Quartile 2 & 0.93 & (0.85 to 1.02$)$ & 0.124 \\
\hline Quartile 3 & 1.01 & (0.91 to 1.12 ) & 0.811 \\
\hline Highest quartile & 0.95 & (0.84 to 1.07$)$ & 0.387 \\
\hline Constant & 0.06 & (0.04 to 0.07$)$ & 0.000 \\
\hline
\end{tabular}

communities with the lowest quartile of privately insured individuals (OR 1.43, 1.66 and 1.51 for highest, 3rd quartile and 2nd quartile, respectively, $\mathrm{p}<0.001)$. Communities with a higher per cent of minorities also had higher odds of having a UCC (OR 9.14, 8.54, and 4.09, for highest, 3rd quartiles and 2nd quartiles, respectively, $\mathrm{p}<0.001)$. Communities with a higher percentage of the elderly were not significantly more or less likely to have a UCC.

Descriptive statistics and ORs from logistic regression results using communities with any UCC, regardless of whether the UCC is hospital based or not, are included in online supplementary appendix tables 3 and 4 . The sample encompassed 8119 UCCs. The results are very similar to our primary analysis of non-hospital-based UCCs, though highest quartile of income level is not significant in the regression (OR 1.06, $\mathrm{p}=0.432$ ).

\section{DISCUSSION}

It has been hypothesised that the recent spurt in growth of the UCC industry is due to the public's growing acceptance of UCCs as reliable providers of care. ${ }^{1}$ However, our research shows that the growth has not been uniformly distributed, much like retail clinics. ${ }^{12}$ UCCs selectively tend not to serve rural areas, areas with a high concentration of low-income patients, and areas with a low concentration of privately insured patients. This uneven distribution may potentially exacerbate health disparities and further compound the high and expanding barriers to accessing care faced by these patients. ${ }^{23} 24$ Low-income patients are also those who have been most impacted by ED closures. ${ }^{19}$

At the same time, our results also show that UCCs seem to locate in areas with high proportions of minorities, which could serve to mitigate healthcare disparities associated with race and ethnicity. Given that we find that UCCs locate in urban areas with higher proportions of privately insured patients and lower proportions of low-income patients, one potential explanation is that the decisions to locate in these areas are due to pure economic considerations that are independent of race.

Our findings of UCCs' preferential location in communities with higher income and more privately insured patients suggest that there may be financial implications for other services, such as emergency and primary care, which provide care for many of the types of conditions that UCCs treat. ${ }^{9}$ UCCs may attract profitable patients 
away from those emergency departments and primary care, and they may specifically threaten the financial viability of safety-net providers that may depend on insured or more profitable patients to cross-subsidise the unreimbursed care they do provide for the community. These implications should be balanced against the possibility that the growth of UCCs may alleviate the crowding and excess demand for emergency and primary care, and potentially provide care at a lower cost. ${ }^{8}$

\section{Limitations}

There are several limitations to this study. First, because data from UCAOA is self-reported, the list is likely not $100 \%$ comprehensive, though the final number of UCCs compiled in our data is similar to what has been previously studied. ${ }^{2}$ Second, ZIP codes have varying geographic sizes and populations, and the presence or absence of a UCC in an individual's ZIP code may not perfectly reflect whether that individual has meaningful access to UCCs. We believe that the catchment area is likely smaller than most ZIP codes, which would suggest that UCCs may have even greater ability to influence which populations they target or avoid. Third, our study is limited to geographic accessibility to UCCs and does not encompass other important dimensions of healthcare access, such as the types of services available or their affordability. ${ }^{25}{ }^{26}$ Finally, while we were able to characterise the demographics and other characteristics of communities with UCCs, we were unable to directly characterise the patients who seek care at UCCs due to lack of patient data.

\section{CONCLUSIONS}

Our analysis provides a portrait of the communities served by UCCs and factors associated with their location. We find that the communities served by UCCs tend to be urban and have high levels of income and private insurance. We also show that these factors are independently associated with the odds of having a UCC within the community, which is consistent with the financial incentives and the largely for-profit nature of this industry. Our findings are a crucial starting point for discussion regarding access to UCCs and how to ensure that the rapid growth of UCCs improves patient care for all patients.

Acknowledgements The authors are grateful to Max Pillsbury, BA, Peggy Wong, BA, and Sarah Sabbagh, MPH (UCSF) for their assistance. They would like to thank the Urgent Care Association of America for the use of their data. The authors would also like to acknowledge the UCSF Open Access Publishing Fund for supporting this article.

Contributors RYH and STL contributed to study concept and design, analysis and interpretation of data. STL contributed to acquisition of data, drafting of manuscript, statistical analysis, and obtained funding. RYH contributed to critical revision of the manuscript for important intellectual content and study supervision.

Funding This work was supported by the National Institute on Minority Health and Health Disparities, National Institutes of Health grant number R25MD006832.

\section{Competing interests None declared.}

Provenance and peer review Not commissioned; externally peer reviewed.

Data sharing statement No additional data are available.

Open Access This is an Open Access article distributed in accordance with the Creative Commons Attribution Non Commercial (CC BY-NC 4.0) license, which permits others to distribute, remix, adapt, build upon this work noncommercially, and license their derivative works on different terms, provided the original work is properly cited and the use is non-commercial. See: http:// creativecommons.org/licenses/by-nc/4.0/

\section{REFERENCES}

1. Weinick RM, Betancourt RM. No appointment needed: the resurgence of urgent care centers in the United States: California HealthCare Foundation, 2007. http://www.chcf.org/publications/2007/ 09/no-appointment-needed-the-resurgence-of-urgent-care-centersin-the-united-states (accessed Aug 2014).

2. Weinick RM, Bristol SJ, Marder JE, et al. The search for the urgent care center. JUCM 2009;3:38-40.

3. Weinick RM, Bristol SJ, DesRoches CM. Urgent care centers in the US: findings from a national survey. BMC Health Serv Res 2009;9:79.

4. Derlet RW. Overcrowding in emergency departments: increased demand and decreased capacity. Ann Emerg Med 2002;39:430-2.

5. Kellermann AL. Crisis in the emergency department. $N$ Engl J Med 2006;355:1300-3.

6. Hsia RY, Kellermann AL, Shen YC. Factors associated with closures of emergency departments in the United States. JAMA 2011;305:1978-85.

7. Bodenheimer T, Pham HH. Primary care: current problems and proposed solutions. Health Aff (Millwood) 2010;29:799-805

8. Merritt B, Naamon E, Morris SA. The influence of an urgent care center on the frequency of ED visits in an urban hospital setting. $A m$ $J$ Emerg Med 2000;18:123-5.

9. Weinick RM, Burns RM, Mehrotra A. Many emergency department visits could be managed at urgent care centers and retail clinics. Health Aff (Millwood) 2010;29:1630-6.

10. Creswell J. Race is on to profit from rise of urgent care. New York Times 2014 (cited 10 July 2014). http://www.nytimes.com/2014/07/ 10/business/race-is-on-to-profit-from-rise-of-urgent-care.html?_r=0

11. Becker $S$, Fry T. Healthcare private equity investment -5 areas to examine in 2014: hospitals and health systems, pain management and anesthesia, ambulatory surgery centers, urgent care and dental practice management: Becker's Hospital Review 2014 http://www. beckershospitalreview.com/leadership-management/healthcareprivate-equity-investment-5-areas-to-examine-in-2014-hospitals-andhealth-systems-pain-management-and-anethesia-ambulatorysurgery-centers-urgent-care-and-dental-pract.html (accessed 1 Aug 2014).

12. Pollack $\mathrm{CE}$, Armstrong $\mathrm{K}$. The geographic accessibility of retail clinics for underserved populations. Arch Intern Med 2009;169:945-9.

13. Horwitz LE. A hostile state for urgent care centers. Arizona: Urgent Care Association of America, 2005.

14. Urgent Care Association of America. The case for urgent care. 2011 http://c.ymcdn.com/sites/www.ucaoa.org/resource/resmgr/Files/ WhitePaperTheCaseforUrgentCa.pdf (accessed Aug 2014).

15. 2010 Census: US Census Bureau (cited 1 August 2014). http://www. census.gov/2010census/

16. American Community Survey. 2012 American Community Survey 1-Year Estimates. United States Census Bureau. 2012. http://factfinder.census.gov/faces/tableservices/jsf/pages/ productview.xhtml?src=bkmk (accessed Aug 2014).

17. Area Resource File. Health Resources and Services Administration. Rockville, MD: Bureau of Health Profession., 2011.

18. United States Department of Agriculture Economic Research Service. Measuring rurality: rural-urban commuting area codes 2005 (cited 21 August 2013). http://www.ers.usda.gov/briefing/Rurality/ RuralUrbanCommutingAreas/

19. Hsia RY, Shen YC. Rising closures of hospital trauma centers disproportionately burden vulnerable populations. Health Aff (Millwood) 2011;30:1912-20.

20. Hsia R, Shen YC. Possible geographical barriers to trauma center access for vulnerable patients in the United States: an analysis of urban and rural communities. Arch Surg 2011;146:46-52.

21. Shen YC, Hsia RY. Changes in emergency department access between 2001 and 2005 among general and vulnerable populations. Am J Public Health 2010;100:1462-9. 
22. Shortage designation: health professional shortage areas \& medically underserved areas/populations: U.S. Department of Health and Human Services Health Resources and Services Administration (cited August 2014). http://bhpr.hrsa.gov/shortage/

23. US Department of Health and Human Services. National Healthcare Disparities Report. AHRQ Publication No. 11-0005; 2013.
24. Institute of Medicine Committee on the Future of Emergency Care in the USHS. Hospital-based emergency care: at the breaking point. Washington DC: National Academy of Science, 2006.

25. Pechansky R, Thomas JW. The concept of access. Med Care 1981;19:127-40.

26. Gulliford M, Figueroa-Munoz J, Morgan M, et al. What does' access to health care'mean? J Health Serv Res Policy 2002;7:186-8. 